Assessing Security Needs of the multifaceted relationships of Energy and Water Providers

Noah Goldstein, Robin Newmark, Liz Burton, Debbie May, Jim McMahon, Camilla Dunham Whitehead, Girish Ghatikar

September 5, 2007 
This document was prepared as an account of work sponsored by an agency of the United States government. Neither the United States government nor Lawrence Livermore National Security, LLC, nor any of their employees makes any warranty, expressed or implied, or assumes any legal liability or responsibility for the accuracy, completeness, or usefulness of any information, apparatus, product, or process disclosed, or represents that its use would not infringe privately owned rights. Reference herein to any specific commercial product, process, or service by trade name, trademark, manufacturer, or otherwise does not necessarily constitute or imply its endorsement, recommendation, or favoring by the United States government or Lawrence Livermore National Security, LLC. The views and opinions of authors expressed herein do not necessarily state or reflect those of the United States government or Lawrence Livermore National Security, LLC, and shall not be used for advertising or product endorsement purposes.

This work performed under the auspices of the U.S. Department of Energy by Lawrence Livermore National Laboratory under Contract DE-AC52-07NA27344. 


\title{
Assessing Security Needs of the multifaceted relationships of Energy and Water Providers
}

September 29, 2007

\begin{abstract}
Noah C. Goldstein*, Robin Newmark**, Liz Burton, Debbie May
\end{abstract} Lawrence Livermore National Laboratory

\section{Jim McMahon ${ }^{\star * *}$, Camilla Dunham Whitehead, Girish Ghatikar Lawrence Berkeley National Laboratory}

UCRL-TR-234269

* (925) 423-3916, Goldstein8@1lnl.gov

** (925) 423-3644, Newmark@1lnl.gov

*** (510) 486-6049, JEMcMahon@lbl.gov 


\section{Abstract}

In the near future, the United States will be facing constraints on energy availability due to the heightened demand for both energy and water, especially during droughts and summers. Increasing stress on the inextricably linked resource availability of both water and energy can be mitigated with integrated planning. Exchanging data is an important component to current and future mitigation approaches within the Energy-Water Nexus. We describe the types of relationships that are formed in the United States EWN, and address the data sharing obstacles within. Approaches to removing the obstacles of data sharing are presented, based on case studies.

\section{Executive Summary}

The key to integrated planning in the Energy-Water Nexus is open collaboration between stakeholders. Yet before collaboration begins, stakeholders have to commit to working together, at least to achieve their individual goals. Before the discussion of data and models begins, stakeholders need to address their personal and organizational concerns, as successful relationships between stakeholders are imperative in this process.

Once stakeholders can identify common goals and data needs, the nature of the relationship and type of entity involved will determine that appropriate security and data sharing mechanism. This can be greatly aided by tools such as:

1) Published data and security standards.

2) Readily available case studies of success stories.

3) People who can facilitate the data sharing.

4) Available technological infrastructure to take advantage of the best and newest computer network tools.

To reiterate, large enterprise tools are not always a viable solution; Standards-based data dissemination is a far stronger option. For security concerns, the mechanism depends on the particular relationship or situation.

\section{Key Findings}

When developing both data management policies and systems that address the obstacles to data sharing in the EWN, there are multiple security mechanisms to consider. These include:

- Identification and authentication

- Authorization

- Access control techniques

- Confidentiality

- Data generalization / summarization

While not exhaustive, this list of security considerations illustrates some of the variety of options that already exist for providing security is a data sharing environment. It is important to note that all of these are "technical" mechanisms that can be applied within/across systems to enforce security policy. For EWN issues, the real challenge lies in defining that security policy. 
From other industries, a number of lessons and best practices can be applied to data sharing in the EWN:

US Census

- Summarization and Generalization

Intelligence Community

- Pedigree / provenance of data

Securities and Exchange Commission (SEC)

- Secure network protocols

- Data confidentiality between public/private/government entities

Department of Defense

- Early consensus of Stakeholders on standards and methodology

Food and Drug Administration

- Formalization of Data Standards

- Confidentiality

As evidenced in the case studies, there is no cookie-cutter recipe for secure data sharing. Information security within the EWN necessitates understanding of the relationships, data needs and cultural context of the stakeholders involved. However, through mutually agreed upon and consistent data sharing, modeling, and, in turn, integrated planning, energy and water needs can be met at the local, regional and national level. 


\section{Contents}

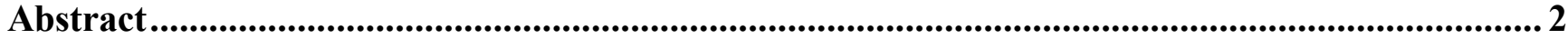

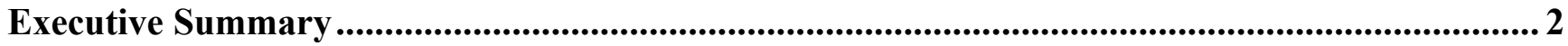

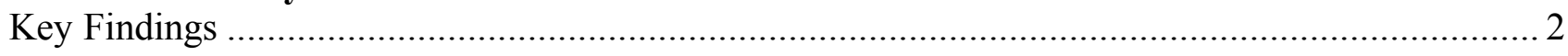

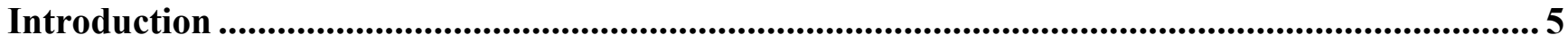

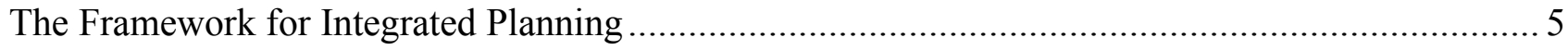

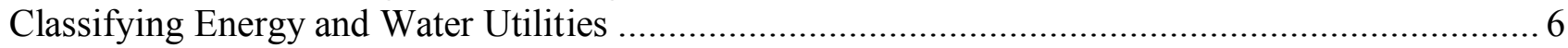

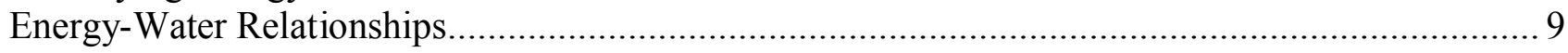

Publicly Available Data ..............................................................................................................9

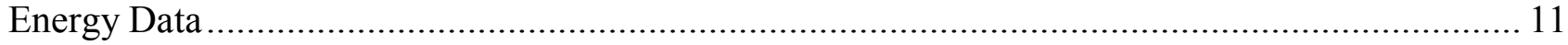

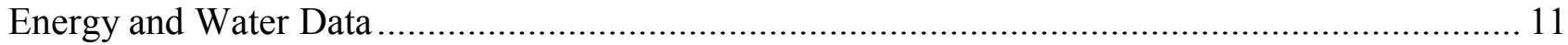

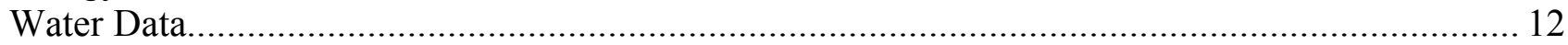

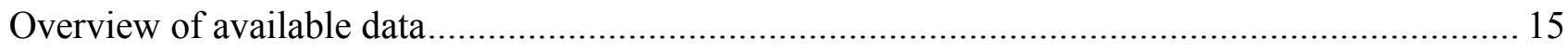

The Challenges to Data Sharing................................................................................................ 15

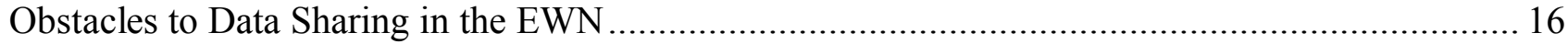

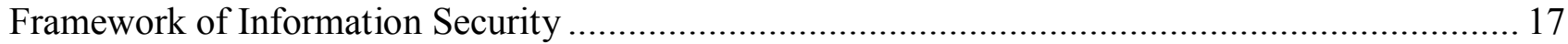

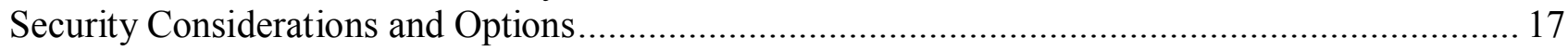

Lessons Learned: Sharing and Protection Mechanisms from other Information Domains .............. 18

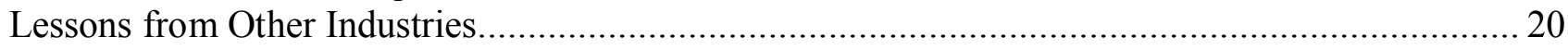

Examples of Complex Relationships between Energy and Water Entities................................... 24

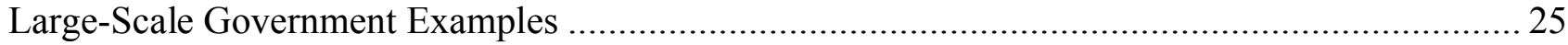

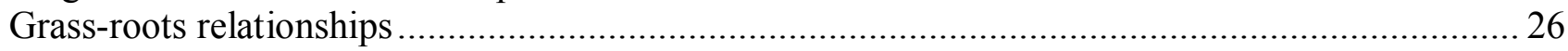

Third-Party / Consultant Interactions.......................................................................... 28

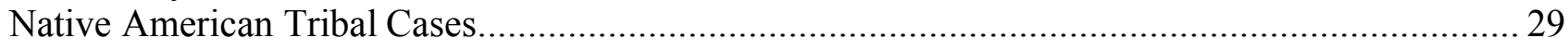

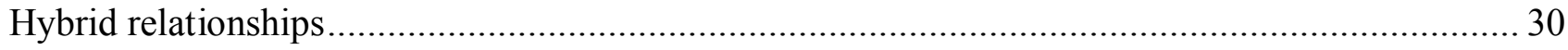

Choosing Appropriate Security for Data Sharing Activities........................................................ 31

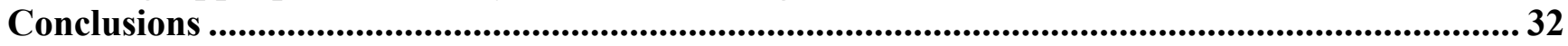

Acknowledgements ...................................................................................................................... 33

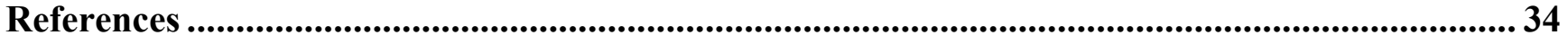




\section{Introduction}

The continued security and economic health of the U.S. depends on a sustainable supply of both energy and water. These two critical resources are inextricably linked - the production of energy requires large volumes of water, while the treatment and distribution of water is equally dependent upon readily available, low-cost energy. We refer to this linkage as the Energy-Water Nexus (EWN). Multiple analyses have indicated that in the near future, the United States will be facing constraints on energy availability due to the heightened demand for both energy and water, especially during droughts and summers (EPRI, 2002; 2003). This is due to many factors, including increased demand from electric and water consumers, increases in drought, and the tightly linked, yet often overlooked, nature of energy generation and water distribution. This is particularly true in the Western States, where cities are surrounded by deserts and supplied by water delivered hundreds of miles from its sources. For example, selected Arizona aquifers are being drawn at rates ten times that of their recharge rates (Gleick, 1998), while the state's population is forecasted to double to 11 million by the year 2030 (U.S. Census Bureau, 2005). Population as a whole in the Southwest is forecasted to grow by $64 \%$ from 2000 to 2040 , using middle estimates from the U.S. Census, corresponding to a $5 \%$ increase in withdrawal of fresh water (Brown, 2000). The same analysis forecasts a $33 \%$ increase in thermoelectric cooling water demand for the Southwest in 2040, relative to 2000 levels. There is little doubt that the Southwest, and the nation as a whole, is on a potentially unsustainable trajectory. If deserts continued to be developed, scarce water resource continued to be utilized beyond their natural recharge rates, and no new innovative approaches to the integrated use of water and energy are implemented, the semi-arid regions of the U.S. may be constrained economically, environmentally degraded, with potentially severe changes in the social fabric.

In order to plan for this future constraint, an integrated approach to resource planning, focusing on the relationship between energy and water systems, needs to be developed at all levels of energy and water supply communities. Integrated resource planning of energy and water would allow for a cohesive and far-sighted approach that could incorporate the changes in economy, security, and climate that the US will be facing in the coming century. An example of the awareness of the linkages and coupled energy-water savings has been addressed by the California Public Utilities Commission (CPUC 2005), who propose that energy usage is an important factor in water policy decisions. This paper addresses some of the obstacles to the incorporation of an integrated approach to energy-water management and planning, namely the unique relationships between energy and water entities, the confidential and proprietary nature of data, and security concerns of stakeholders. We present a taxonomy of these relationships, address the obstacles to sharing data, and propose methods for facilitating data sharing within the US energy and water providers. We also present a brief overview of Information Security and best practices based on lessons learned from government and corporate examples.

For the purposes of consistency, EWN Stakeholders, such as electric utility companies, water, and power companies, will be referred to as Utilities. While some water-related stakeholders may not agree with this term, the authors feel it is applicable in most cases, and is not intended to distort the goals of the individual stakeholders in the EWN.

\section{The Framework for Integrated Planning}

The three components of integrated planning within the EWN are data, models, and policy (Figure 1). Given the need for collaboration between EWN stakeholders, each of these must be resolved to some 
degree to develop the plan. Data may or may not be available, and if it exists, it may not necessarily be collected at an appropriate spatiotemporal scale. Policy considerations may be intuitive, qualitative or quantifiable in nature. To link the two, models can demand high resolution data or some qualitative suggestions of data, determined by expert opinion.

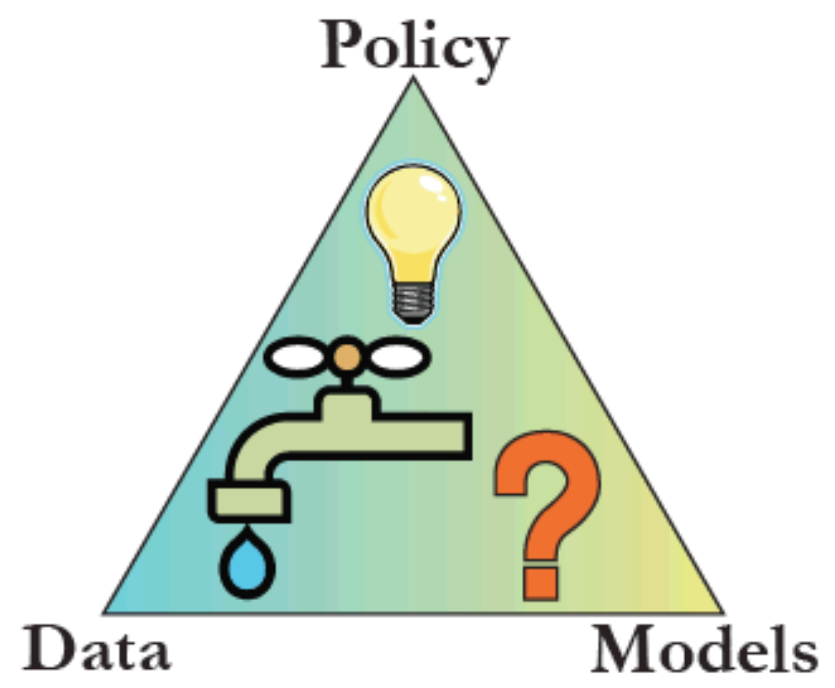

Figure 1. The three components of Integrated Planning in the EWN.

This work focuses on the integrative ability within the EWN of Data, and to a lesser degree Models, as operational components of planning. The Data and Models of concern are those that relate to the operating and forecasting tools of Energy and Water planning, for example, Energy-related data includes:

1) Electricity demand by region

2) Energy production by type of a utility

3) Water consumption and use by specific energy generation types

4) Planned electricity production by a utility

5) Forecasted energy needs by a region

6) Forecasted energy costs

Examples of Water-related data include:

7) Available water in aquifers and reservoirs

8) Water demand of populated, agricultural or industrial stakeholders

9) Snow pack depth

10) Stream flows within a watershed

11) Forecasted water costs

These data can vary at their native spatial and temporal scales. Examining how policy effects integrated planning within the EWN is on the periphery of the scope of this work, yet is mentioned when appropriate.

\section{Classifying Energy and Water Utilities}

The jurisdictional, organizational and geographical structures of energy and water utilities can vary enormously and inconsistently throughout the United States. Due to this variability, the relationships between these utilities are multifaceted and diverse in classification as well. This leads to broad challenges in describing and classifying the relationships between the "major players" within the 
EWN. This being said, the major divergence in the types of companies is in ownership. According to an Energy Information Administration (EIA) publication (EIA, 1999), utilities can be:

1. Investor Owned

2. Federally Owned

3. Other Publicly Owned

4. Cooperatively Owned

In the U.S., about $75 \%$ of energy companies are investor-owned utilities (IOUs), $25 \%$ publicly-owned (EIA, 2007). The water side is quite different. Of the 400 billion gallons per day withdrawn for use, most of the water is untreated and used for agriculture and thermoelectric production. Only $11 \%$ of water travels through utilities for drinking water use (Hutson, 2005). Most drinking water utilities are publicly-owned (54\%); however the ratio between publicly- and privately-owned varies from state to state (Mann, 1993). Although community drinking water systems owned by the private sector account for about half of all such systems, they serve only about 15 percent of households (Congressional Budget Office, 2002). For example, in California, about $90 \%$ of the population is served by publiclyowned water utilities (Neal, 1996). Each utility can be affected by different (sub-federal) reporting regulations, according to state and local jurisdiction. Ownership dictates the drivers that form the basis for priorities within the utility.

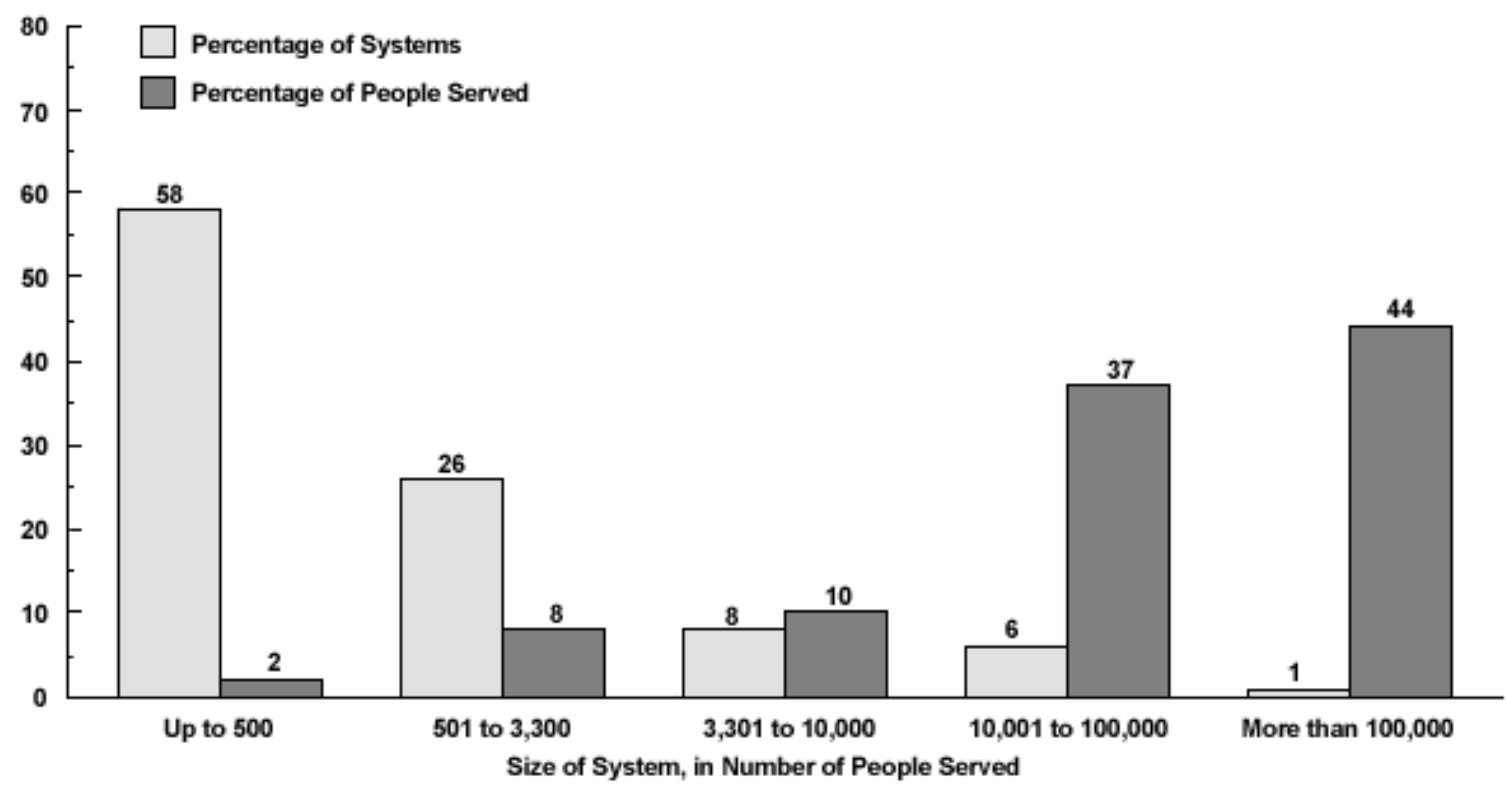

Figure 2: The variety of the size and numbers of people served by water suppliers in the US (CBO 2002) Note: The total number of water systems is 53,783. The total number of people served is $264,145,129$.

Investor Owned Utilities (IOU) are beholden to their shareholders and usually operate as for-profit companies. Their goal is the improving the bottom line. Depending on the State or region, IOUs can be subject to regulation, or unregulated. Aside from federally mandated data collection, there have been instances of data and proprietary models being shared or widely distributed with State or Federal regulatory agencies, but there is no requirement for the IOUs to do so. 
Federally Owned Utilities can exist at any geographical region, but mostly pertain to large, multistate areas (like the Tennessee Valley Authority (TVA)). Their goal is the preservation of the resource they manage. They are primary producers and wholesalers of electricity and water distribution. They may be forthcoming in sharing data, but may not have been required to do so.

Other Publicly Owned Utilities are smaller utilities that include municipal, public power districts, state authorities and irrigation districts. They operate as non-profits and their goal is to minimize cost to the consumer. They compete with other utility types and therefore are protective of their data.

Cooperatively Owned Utilities (Co-ops) are customer owned. While they are not "major players" at the national level, they provide significant amounts of water and electricity to the public. It is unclear what their data sharing mandates or tendencies are, and how consistent they might be from utility to utility.

\section{Other Institutional Players}

In addition to the utilities, other institutions may participate in planning activities or be involved in the collection and dissemination of key data necessary for integrated planning. These include the following:

- Regulatory entities such as the EPA, FERC, and various State utility, environmental and coastal commissions,

- Administrative entities such as the U.S. Army Corps of Engineers, the U.S. Bureau of Reclamation or state and local agencies,

- Data collection agencies such as the U.S. Geological Survey, the Energy Information Administration or state agencies

In some cases, the entity that owns or administers the energy also has jurisdiction over its water (like the Tennessee Valley Authority, (TVA) or Pacific Gas and Electric (PG\&E) Hydro). In addition, the utility headquarters may be located in a different state.

In the energy domain, different companies can serve single or multiple functions across the spectrum of distribution, generation, and transmission (i.e., be vertically integrated). These companies may be public or privately owned, or created by an agreement between public and private entities.

In the water domain, agencies at the State or Federal level have significant jurisdiction over the resource, but are not responsible for generating power. For example, the US Army Corps of Engineers is in charge of maintaining transportation and dock utility of the Ohio River within the TVA, but is not responsible for power. There are a number of different responsibilities of water utilities, including storage, drinking water, wastewater management, agricultural, and managing industrial water supply. 


\section{Energy-Water Relationships}

Relationships between water and energy utilities are shaped by their jurisdictional, organizational, and geographical structures. Additionally they can occur between any permutation between public and private entities (Figure 3a):

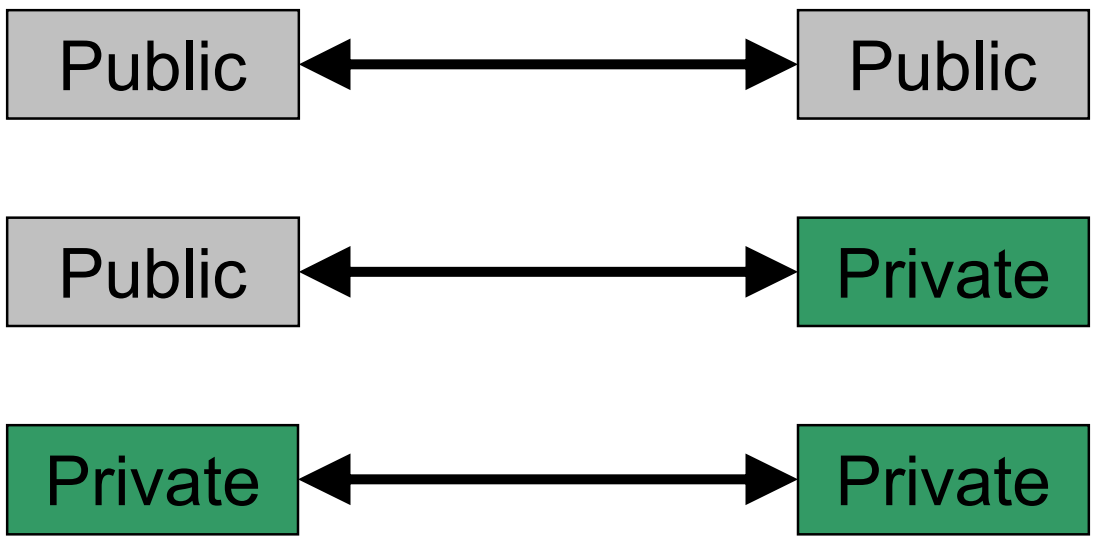

Figure $3 a$
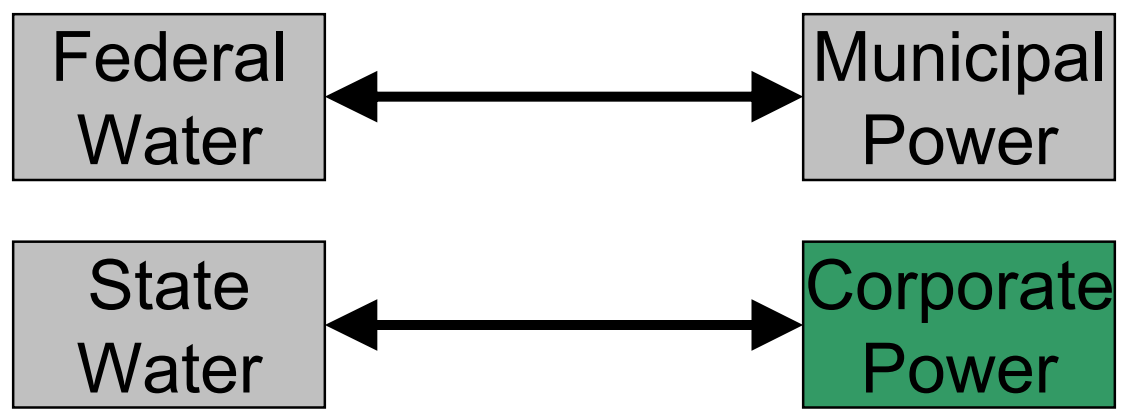

Figure $3 b$

Within each of these relationships or interactions, there are a variety of potential combinations of stakeholder types, for example, federal water agencies can partner with municipal power companies, or state water utilities can partner with investor owned corporate power companies (Figure $3 b$ ).

\section{Publicly Available Data}

Considerable public-domain information is available concerning energy generation, water use by utilities, and regional water availability. Most of these data are collected by state or federal entities, and then summarized based on regions defined by counties or hydrologic unit codes. Many data products are syntheses of other federally collected data products. The following table includes entities that contribute significantly to publicly available water and energy data relevant to potential integrated planning and management of both energy and water resources. 
Table 1 - Energy and Water Data

\begin{tabular}{|c|c|c|c|c|}
\hline Agency & Data Type & Domain/Resolution & Program / Survey Tool & Reference \\
\hline FERC & FERC collects monthly cost and quality of fuels for electric plants & Power Plant & Form 423 & ferc.gov \\
\hline FERC & $\begin{array}{l}\text { FERC collects data regarding plants owned by the utility, monthly } \\
\text { production, the peak load and the connections with the } \\
\text { interconnects (the grid) by } \mathrm{kWh}\end{array}$ & Electric Utility & Form 714 & ferc.gov \\
\hline $\begin{array}{l}\text { U.S. } \\
\text { Department } \\
\text { Of } \\
\text { Agriculture } \\
\text { (USDA) }\end{array}$ & $\begin{array}{l}\text { ERS collects per acre pumping energy costs, number of irrigation } \\
\text { wells and pumps by energy source }\end{array}$ & Farms & $\begin{array}{l}\text { Economic Research Service } \\
\text { (ERS) }\end{array}$ & www.ers.usda.gov/data \\
\hline USDA & $\begin{array}{l}\text { NWCC datasets include information on (1) water and climate and } \\
\text { (2) conservation planning. }\end{array}$ & $\begin{array}{l}\text { Stream, State, } \\
\text { Reservoir }\end{array}$ & $\begin{array}{c}\text { National Water And Climate } \\
\text { Center }\end{array}$ & www.wcc.nrcs.usda.gov/wsf \\
\hline EIA & $\begin{array}{l}\text { Consumptive and non-consumptive water used by all steam- } \\
\text { electric power plants in the country }\end{array}$ & Power Plant & Form 767 & www.eia.doe.gov/cneaf/electricity/page/eia767.html \\
\hline EIA & $\begin{array}{l}\text { EIA collects consumptive water use by sector in its energy } \\
\text { surveys }\end{array}$ & $\begin{array}{l}\text { House, Commercial } \\
\text { Enterprise Building }\end{array}$ & $\begin{array}{l}\text { RECS, CBECS Residential } \\
\text { and Commercial/Business } \\
\text { Energy Consumption Survey }\end{array}$ & $\begin{array}{l}\text { www.eia.doe.gov/emeu/recs } \\
\text { www.eia.doe.gov/emeu/cbecs }\end{array}$ \\
\hline EPA & $\begin{array}{l}\text { EGRID has data on emissions and resource mix for virtually every } \\
\text { power plant and company that generates electricity }\end{array}$ & Power Plant & $\begin{array}{l}\text { Emissions \& Generation } \\
\text { Resource Integrated Database } \\
\text { (EGRID) }\end{array}$ & www.epa.gov/cleanenergy/egrid/index.htm \\
\hline EPA & $\begin{array}{l}\text { CWNS contains wastewater data from publicly owned wastewater } \\
\text { collection and treatment facilities }\end{array}$ & $\begin{array}{c}\text { Publicly Owned } \\
\text { Wastewater } \\
\text { Collection And } \\
\text { Treatment Facilities } \\
\end{array}$ & $\begin{array}{l}\text { Clean Water Needs Survey } \\
\text { (CWNS) }\end{array}$ & www.epa.gov/cwns \\
\hline EPA & $\begin{array}{l}\text { The Safe Drinking Water Information System (SDWIS) contains } \\
\text { information about public water systems and their violations of } \\
\text { EPA's drinking water regulations. }\end{array}$ & $\begin{array}{l}\text { Public Water } \\
\text { Systems }\end{array}$ & $\begin{array}{l}\text { Safe Drinking Water } \\
\text { Information System (SDWIS) }\end{array}$ & www.epa.gov/enviro/html/sdwis \\
\hline EPA & Discharge and water quality data, other releases & $\begin{array}{l}\text { Water Quality, } \\
\text { Discharge }\end{array}$ & Envirofacts Database & www.epa.gov/enviro/ \\
\hline EPA & $\begin{array}{l}\text { STORET (STOrage and RETrieval) is a repository for water } \\
\text { quality, biological, and physical data }\end{array}$ & $\begin{array}{l}\text { Water Quality } \\
\text { Reports }\end{array}$ & $\begin{array}{c}\text { Storage And Retrieval System } \\
\text { (STORET) }\end{array}$ & www.epa.gov/storet/index.html \\
\hline $\begin{array}{l}\text { U.S. } \\
\text { Geological } \\
\text { Survey } \\
\text { (USGS) } \\
\end{array}$ & $\begin{array}{l}\text { National Water Information System Web site (NWISWEB) has } \\
\text { real-time water data and water data for the nation }\end{array}$ & $\begin{array}{l}\text { Surface Water, } \\
\text { Groundwater, Water } \\
\text { Quality, And Site } \\
\text { Information. } \\
\end{array}$ & NWISWEB & waterdata.usgs.gov/nwis \\
\hline USGS & $\begin{array}{l}\text { Waterwatch collects current stream flow conditions (floods and } \\
\text { high flows, drought, monthly stream flows, and groundwater). }\end{array}$ & Streams & WaterWatch & water.usgs.gov/waterwatch \\
\hline USGS & USGS collects national water quality assessments (NAWQA) & $\begin{array}{c}\text { Chemical, } \\
\text { Biological, And } \\
\text { Physical Water } \\
\text { Quality Data From } \\
\text { 42 Study Units }\end{array}$ & BASINS & water.usgs.gov/nawqa \\
\hline $\begin{array}{l}\text { American } \\
\text { Water Works } \\
\text { Association } \\
\text { (AWWA) }\end{array}$ & $\begin{array}{l}\text { Statistics from surveys of American and Canadian drinking water } \\
\text { utilities. Categories of information include income, expenses, } \\
\text { capital needs, conservation programs, water losses, rate structures, } \\
\text { customer demographics, finances, and revenues. }\end{array}$ & $\begin{array}{l}\text { Drinking Water } \\
\text { Utilities. }\end{array}$ & WATER:ISTATS. & www.awwa.org/bookstore/product.cfm \\
\hline
\end{tabular}


More detail into the table entries are included in the following section:

\section{Energy Data}

The following are federal sources of data pertaining to energy use.

\section{Federal Energy Regulatory Commission (FERC)}

FERC is an independent federal agency that regulates the transmission of energy across state lines. While they monitor and regulate electricity, oil and natural gas, they also licenses and re-licenses Hydropower and natural gas pipeline projects. FERC also monitors the state of the energy system and monitors and enforces federal rules. The Commission collects numerous data from Energy Utilities on an annual basis. These pertain to the production and financial details of the Utilities, as well as forecasts for production and demand. A fair number of these forms are not in the public domain due to their proprietary nature, yet two forms relating to Electricity production, Forms 423 and 714 are publicly available. Form 423 "Monthly Report of Cost and Quality of Fuels for Electric Plants" collects data on the source, volume, and the sulfur content (of Coal) of fuel sources for electricity plants, namely natural gas and coal. Data is available from the present to the 1970s. Form 714 "Annual Electric Control and Planning Area Report" contains different data, such as the actual plants owned by the utility, their monthly production, the peak load and the connections with the interconnects (the grid) by kWh. Due to the sensitive nature of form 715, it has since been removed from public dissemination, as it contained detailed annual electricity transmission planning and evaluation, which now can be considered sensitive material after 9/11. FERC also make available data pertaining to natural gas and its utilities, but it does not as directly relate to concerns within the EWN. It should be noted that FERC does not have jurisdiction over many kinds of energy utilities (such as nuclear) and therefore does not collect data on those state-regulated utilities.

\section{Energy and Water Data}

The following are federal sources of data pertaining to energy and water use.

\section{U.S. Department of Agriculture}

ERS summarizes farm numbers, per acre pumping (energy) costs, and the number of irrigation wells and/or pumps by energy source, all by farm size class

The National Water and Climate Center supports both planning and data acquisition, and management. Their datasets include information on (1) water and climate and (2) conservation planning.

\section{Energy Information Administration}

Among the many types of data EIA collects are data on water used in hydropower generation and cooling. With respect to water used for cooling, EIA Form 767 records the consumptive and nonconsumptive water used by all steam-electric power plants in the country. Annual data summaries are available back to 1996. Consumptive use by nuclear plants also is recorded. No data are collected on the volumes of water consumed by energy-related activities such as refineries or petroleum pumping.

EIA developed and applies the National Energy Modeling System (NEMS) for forecasting energy use across sectors and regions. The NEMS model considers water supply only as related to hydroelectric 
generation. In the model, water use is determined based on historical generation, not water supply (see Electricity Demand Market Module documentation, EIA, 2004).

EIA maintains the Operations Security Program, which oversees the protection of data collected by their many surveys and distributed in their reports. This program protects data for reasons related to both homeland security and competitive security. EIA relies on the Confidential Information Protection Statistical Efficiency Act (CIPSEA) both to use confidential data for statistical purposes and to protect the confidentiality of the data supplied (Jay Casselberry, EIA, personal communication).

Currently EIA is proposing to stop collecting Form 767 data because of budgetary constraints, specifically the $\$ 600 \mathrm{~K}$ annual cost for collecting and compiling the data. Both USGS and EPA have requested that EIA reverse this decision. Form 767 is the only means for collecting nationwide data on water use by the energy sector. Without Form 767 data, many of the points and discussions proposed in this work

EIA conducts the nation's premiere surveys on energy consumption within major economic sectors. EIA surveys are highly detailed, constructed to be statistically representative of the entire population, and indispensable for analysis and policy planning. For more than 20 years EIA's detailed surveys have collected statistically representative data for residences, commercial establishments, and manufacturing plants nationwide. Although these comprehensive surveys focus on energy consumption, EIA has incorporated questions about water end-uses into its Residential Energy Consumption Survey and is in the process of including such questions in its Commercial and Business Energy Consumption Survey. EIA has not yet considered collecting water information through its Manufacturing Energy Consumption Survey.

Generally, the issues of water rights and supply have fallen under non-federal jurisdiction. Although no agency is responsible for regulating water demand, water demand has been addressed somewhat on the federal level since 1994, when the U.S. Congress mandated that the U.S. Department of Energy develop standards governing rates of water flow for selected commercial and residential appliances.

\section{Water Data}

The following are federal and private sources for data regarding water availability, consumption, and quality.

\section{U.S. Environmental Protection Agency}

The U.S. Environmental Protection Agency (EPA) establishes and enforces water quality standards for drinking water and for returning wastewater effluent to public supply or the nation's waters. The EPA has a three-part mission with respect to water. EPA (1) enforces federal laws governing clean water and safe drinking water, (2) provides support for municipal wastewater treatment plants, and (3) enacts pollution prevention programs to protect watersheds and sources of drinking water.

EPA maintains various databases, including the five described below.

The Emissions \& Generation Resource Integrated Database (eGRID) contains data on emissions and resource mix for virtually every power plant and company that generates electricity in the United States. By merging data from EIA, EPA, and FERC, eGRID represents more than 5,000 power plants 
and nearly 2,000 generating companies. The just-released eGRID2006 has emission and generation data from 1996 through 2004.

The National Electric Energy Data System (NEEDS) contains information on generating units, which is used to construct "model" plants. The model plants represent existing and planned/committed units that then are incorporated in modeling that utilizes EPA's Integrated Planning Model. NEEDS includes basic geographic, operating, air emissions, and other data on generating units.

EPA periodically collects data through its Clean Water Needs Survey, which contains wastewater data from publicly owned wastewater collection and treatment facilities.

The Safe Drinking Water Information System contains water supply data collected by states and EPA regions. Data are available for every public water system in the country.

The web page for the EPA's STORage and RETrieval System (STORET) has links to state drinking water offices for obtaining local water quality reports.

The Water Information Network contains national and regional information on public watersheds.

\section{U.S. Geological Survey}

With respect to water, the mission of the U.S. Geological Survey (USGS) is to compile the information necessary to understand the nation's water resources and enable policy makers to:

- Minimize loss of life and property due to water-related natural hazards such as floods, droughts, and land movement;

- Effectively manage groundwater and surface-water resources for domestic, agricultural, commercial, industrial, recreational, and ecological uses;

- Protect and enhance water resources for human health, aquatic health, and environmental quality;

- Contribute to wise physical and economic development of the nation's resources for the benefit of present and future generations.

Most states or regions have a USGS Water Science Center that produces an annual Water Data Report or a compilation of Water Resources Data that contains detailed measurements of water flow, levels, and/or discharge associated with rivers, streams, reservoirs, lakes, and groundwater observation wells. The datasets collected by USGS include the four described below.

The National Water Information System Web Site (NWISWeb) provides selected water resources data for approximately 1.5 million sites across the United States from 1857 to the present. NWISWeb has links to Real-time Water Data and Water Data for the Nation (surface water, groundwater, water quality, and site information).

WaterWatch collects and posts information about current stream flow conditions (floods and high flows, drought, monthly stream flows, and groundwater).

The National Water Quality Assessment (NAWQA) program was started in 1991 to collect chemical, biological, and physical water quality data from 42 study units (basins) across the nation. The 
NAWQA data warehouse contains and provides links to the following data, which are complete through September 30, 2005.

- Concentrations of about 2,000 chemical constituents in water, bed sediment, and tissues of aquatic organisms.

- Site, basin, well, and network characteristics, including many descriptive variables.

- Daily stream flow information for fixed sampling sites.

- Groundwater levels for sampled wells.

- Measurements from 7,600 surface water sites and 8,100 wells.

- Results for 49,000 samples analyzed for nutrients and 31,000 samples analyzed for pesticides, as well as for 9,000 samples analyzed for volatile organic compounds.

- Analytical results for 2,500 samples of bed sediment and tissues of aquatic organisms.

- Biological community data for 16,000 fish, algae, and invertebrate samples.

The purpose of the USGS Hydro-Climatic Data Network "is to provide a single, division-wide compilation of discharge stations having periods of record for which the monthly and annual streamflow values are suitable for climatological analysis."

USGS data are compiled into reports geared primarily to the scientific community. Reports include the following.

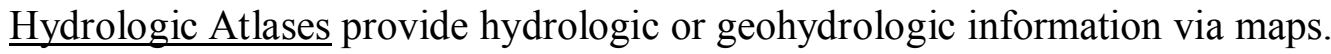

Water Data Reports present hydrologic data gathered from USGS and cooperating agency networks for collecting surface- and groundwater data in each state, Puerto Rico, and the Trust Territories. Records of stream flow, groundwater levels, and water quality provide the hydrologic information that state, local and federal agencies and the private sector need to develop and manage the nation's land and water resources.

Greater detail on volumes of water consumed at the state level can be found in a state's annual USGS Water Data Report or in data often maintained by a state's Department of Water Resources or similar body. Although most states have a water resources or planning governing body, few states collect consumption data and provide it on-line.

\section{US Department of Agriculture}

Economic Research Service (ERS) is a primary source of economic information and research in the U.S. Department of Agriculture. ERS conducts research to inform public and private decision-making on economic and policy issues including, among other subject areas, natural resources and rural development.

The National Water and Climate Center of the U.S. Department of Agriculture (USDA) provides water and climate information to the agricultural sector to benefit food production. The mission of the National Water and Climate Center, which is part of the U.S. Department of Agriculture, is to lead in developing and disseminating water and climate information and technology in support of conserving natural resources. 


\section{American Water Works Association}

The American Water Works Association (AWWA) represents the community of water supply utilities: treatment plant operators and managers, scientists, environmentalists, manufacturers, academicians, and regulators. Members represent more than 4,700 utilities that supply water to roughly 180 million people in North America. AWWA maintains a database of water utility statistics called WATER:ISTATS.

WATER:ISTATS contains statistics from surveys of American and Canadian drinking water utilities. Categories of information include income, expenses, capital needs, conservation programs, water losses, rate structures, customer demographics, finances, and revenues.

\section{Overview of available data}

From the review above, it may appear that there is a vast amount of information available for integrative planning within the EWN. This is true to a significant degree. However, the data presented above is frequently out-dated or generalized to an unusable degree. The types of data that will be of use to integrated planning within the EWN are detailed spatial and temporal data, pertaining to local resources of different types. In addition, auxiliary information, such as demographic model output, economic forecasts, and geological maps, need to be made available, and these are seldom in an easily obtainable and readable form for integrated planning.

\section{The Challenges to Data Sharing}

The challenges to sharing data, both spatial and aspatial, are a non-trivial problem and have previously been addressed in the literature. There have been numerous Federal frameworks established to aid and facilitate data sharing (at the Federal Level) such as the Federal Geographic Data Committee Clearinghouse Registry (FGDC) The Federal Enterprise Architecture Action Plan, Core.gov, and other E-Government Frameworks. However, even though there has been considerable time and effort in creating these tools, they may be largely ineffective in their applications to small-scale, site-specific problems that may arise in the EWN.

Nedović-Budić and Kim (1999) address some of the major obstacles to effective integration:

1.Transferring files between different ... data models and formats imbedded in software developments

2.Moving data between hardware platforms

3.Understanding of the sources, purpose, meaning, and quality of the geo-spatial data

4.Overcoming the proprietary and organizational aspects of information use and exchange.

These four obstacles are contextualized in the EWN in the following section.

Such obstacles can present themselves with even the simplest form of data exchange, given the diversity of stakeholder types within the EWN. 


\section{Obstacles to Data Sharing in the EWN}

A number of obstacles hinder free data sharing between independent utilities or between utilities and researchers. Some of these obstacles are technical, while others are due to the sensitive nature of the data, as described below:

1) Data Models. While data can be shared between companies, they often have to provide it to different regulatory agencies that in turn use different templates for collection (e.g., FERC vs. EIA). These data are not standardized or cross-walked to create a uniform data set. There is no single comprehensive source of energy and water data that can be quickly used for planning purposes. Data are born to specific moments in time and space, be it years, hours, or seconds, and States, counties, watersheds or reaches, respectively. This presents a significant challenge to fusing or consolidating data of different spatial or temporal scales. Typically, data is generalized to the coarsest denominator, or modeled or downscaled to finer resolutions. Using either type of technique takes statistical knowledge and understanding of statistical issues, and can be computationally intensive. The same issues arise with conflating results of system models at different scales.

2) Cross-Platform Transfer. Even with most data collection activities occurring electronically, there is no single consistent platform or mechanism to share data easily. The problem of Windows versus Macintosh operating systems is small compared to large enterprise-level database structures that have had millions of dollars and man-hours invested in.

3) Context and Meaning of Data. Different agencies collect data for their own specific purposes and goals. Additionally, existing data sources (and meters and monitors) were created to answer certain questions, which may or may not coincide with those needed for integrated planning. In some cases the needed data may not be present. For example, we do not have an accurate estimate on how much groundwater is used within California. DWR, in the state water plan, does not even attempt to differentiate between surface and groundwater use for agricultural and municipal purposes (Joe O'Hagan, Personal Communication, 2007). This discrepancy and potential paucity of data also has the additional complication of data being subject to various geographical and administrative data types and reporting rules. This can result in regions that can be geographically close may not be able to share data. Additionally, water and energy boundaries are seldom congruous, and cannot be easily conflated.

4) Proprietary nature of data. This is the most significant hindrance to data sharing. Since private and quasi-private entities compete with other utilities in the market, some data, especially pricing data, is very sensitive. In addition, since many utilities are part of large companies, local sharing could be hindered by the parent companies' competing goals. In the water sector, there is sensitivity about detailed information on pumping, storage and supplemental sources that can be perceived to provide competitive advantage in negotiations with competing or neighboring providers. Another form of proprietary conflict is between consulting companies performing analysis and collection for municipal agencies. In New York City, for example, different consulting agencies compete against each other for city data collection and planning projects, and do not share data as they perceive ownership of the data (Kenya Crosser, BNL, 2007, personal communication). 
There are additional obstacles to data sharing, namely the existence of the data themselves. Some data collection activities, such as annual water level collection at the USGS, have been decreased or have ceased, largely due to budgetary constraints.

\section{Framework of Information Security}

The field of Information Security provides a powerful framework for the establishment of a system where data can be integrated between groups that have not shared data in the past. The six major components of Information Security, confidentiality, possession or control, integrity, authenticity, availability, and utility (Parker, 1995), all contribute to the preservation of data and the appropriate dissemination of data (Figure 6). A system that allows data sharing between water and energy entities must take these six components into account, so that the integrity of the data and the goals of each utility are not compromised.

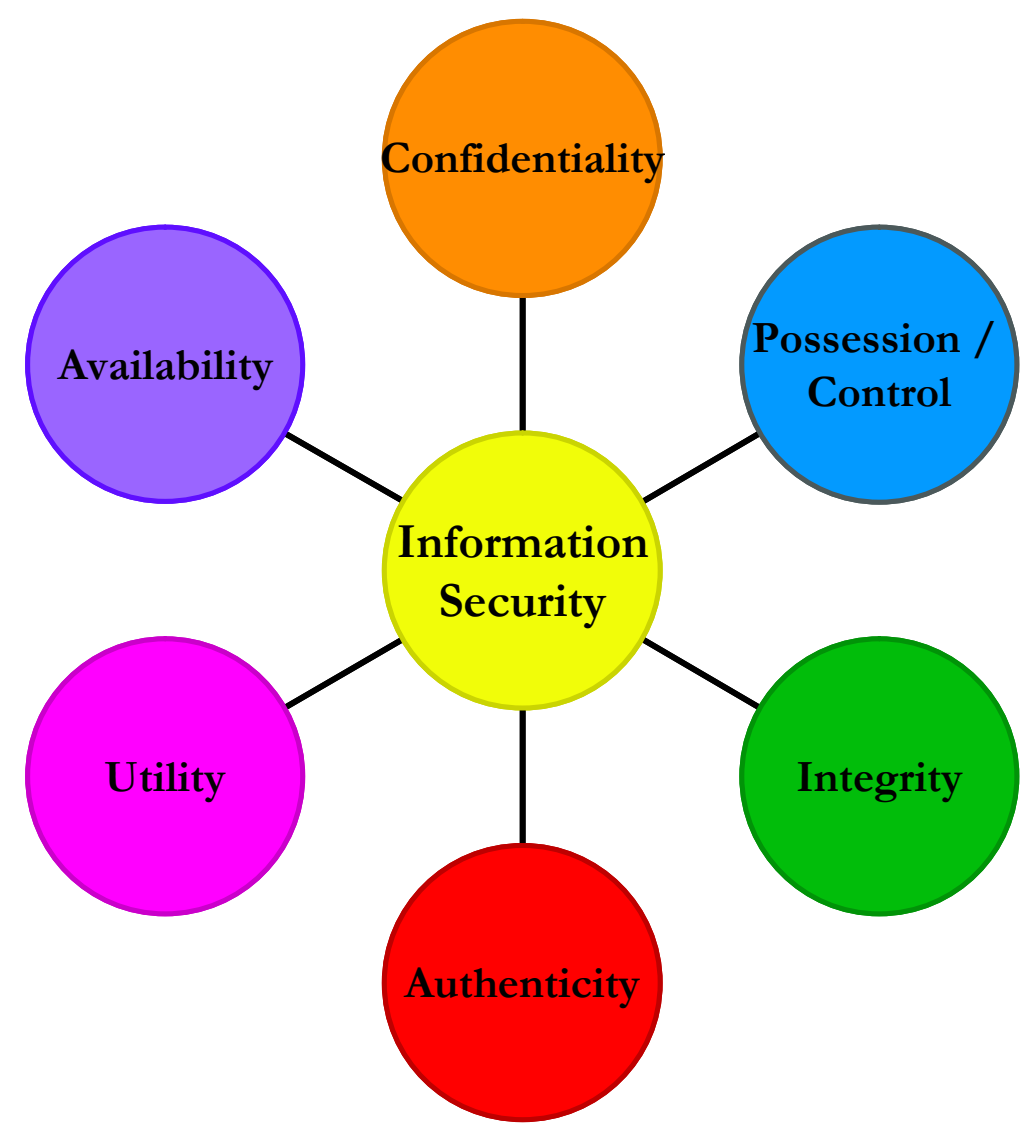

Figure 6. The Six Components of Information Security. After Parker, 1995

\section{Security Considerations and Options}

When developing both data management policies and systems that address the issues described above, there are multiple security mechanisms to consider. These include:

- Identification and authentication: Identification and authentication (I\&A) is a two-step process that determines who can log on to a system. Identification is how a user tells a system who he or she is (for example, by using a username). The identification component of an access control 
system is normally a relatively simple mechanism based on either Username or User ID. Authentication is the process of verifying a user's claimed identity (for example, by comparing an entered password to the password stored on a system for a given username, or verifying a certificate through a Public Key Infrastructure (PKI ) system).

- Authorization: Authorization defines a user's rights and permissions on a system. After a user (or process) is authenticated, authorization determines what that user can do on the system.

- Access control techniques: Access control techniques are generally categorized as either discretionary or mandatory. Discretionary Access Control (DAC) is an access policy determined by the owner of a file (or other resource). The owner decides who is allowed access to the file and what privileges they have. Mandatory access control (MAC) is an access policy determined by the system, not the owner. MAC is used in multilevel systems that process highly sensitive data, such as classified government and military information. A multilevel system is a single computer system that handles multiple classification levels between subjects and objects.

- Confidentiality: In addition to the above mechanisms that provide system and network level protections, encryption is commonly used to provide data confidentiality (and integrity) while data is in transit (and sometimes even when stored). There are numerous encryption systems from which to choose that vary in strength, ease of use, and computational efficiency.

- Data generalization / summarization: The are numerous computational methods available that permit data sharing without revealing raw, unprocessed data - which often alleviates much of the sharing concerns. Many of these mechanisms have already been quantitatively characterized in terms of the protection they provide. This is particularly true for data processing techniques used for Census data, which protected by privacy laws.

This list of security consideration is not exhaustive, but does begin to illustrate some of the variety of options that already exist for providing security is a data sharing environment. It is important to note that all of these are "technical" mechanisms that can be applied within/across systems to enforce security policy. For EWN issues, the real challenge lies in defining that security policy.

\section{Lessons Learned: Sharing and Protection Mechanisms from other Information Domains}

The need to find a middle ground between protecting data and sharing data is not unique to the Energy Water Nexus community. In an effort to identify useful policy or technical mechanisms that could be adopted in EWN, and also to learn from others mistakes we have examined several other information domains' approaches to balancing sharing and security, as well as examined some of the legal framework applicable to EWN issues. We present here our assessment of those lessons learned and discuss how they could potentially be applied in the EWN arena.

\section{Federal Data Sharing Provisions}

There are currently a variety of data dissemination and protection tools and regulations that pertain to data collected by or at the Federal Government. Some of these are meant to protect the data collector, the data user, or the data subject. These provisions are usually cast at the Federal level, resulting into implementation at the agency level. The three most significant of these are:

1. Confidential Information Protection and Statistical Efficiency Act of 2002 (CIPSEA).

2. Freedom of Information Act (FOIA)

3. The Federal Information Security Management Act (FISMA) of 2002 
These provisions establish mechanisms for some of the EWN stakeholders to share data. However, as evidenced from the case studies later in this paper, having provisions in place does not ensure collaboration.

\section{CIPSEA as a data protection mechanism}

The U.S. Government has provided a mechanism for confidential information protection, the Confidential Information Protection provisions of title V, subtitle A, Public Law 107-347, the Confidential Information Protection and Statistical Efficiency Act of 2002 (CIPSEA). CIPSEA is a mechanism for ensuring the protection of data released to public agencies from other public or private parties. This is contrast to the Freedom of Information Act (FOIA), which is a sharing mechanism. CIPSEA trumps FOIA, much in the way that FOIA is negated by a Memorandum of Agreement (MOA), or classification markings.

In terms of application to EWN, CIPSEA has a number of potential issues, listed below:

1.CIPSEA is fairly new. It is not clear that what is and isn't "statistical"-this differentiation is the premise of CIPSEA. There appears to be a great gray area that could take years to be determined by various courts.

2.CIPSEA explicitly restricts other forms of data use i.e. "non-statistical" - even if the data holder agrees, additional disclosure arrangements must be made for the non-statistical uses.

3.What happens if CIPSEA-protected data is accidentally released e.g. a hacker obtains data? CIPSEA may hold the federal agency accountable and liable financially. The wording is not clear, but if there are cases in which this has happened, a precedent has been set. We have not found information regarding this event to date.

4.Given the strict uses under CIPSEA, it might be preferable from a liability standpoint to have the data holders pre-process the data, rather than provide detailed data that cannot be used anyway.

5.CIPSEA does not appear to offer a flexible mechanism for releasing information. Intelligence community data has numerous markings to indicate to whom and on what dates information can be released. CIPSEA has no such specifications. If it did, "non-statistical" sharing might be permitted, say with other Federal agencies, or after the data has aged.

6.CIPSEA document refers to CIPSEA Section 512. Section 512 describes CIPSEA's application to agents of the federal agencies and places additional restrictions. There is no clear wording if or how CIPSEA applies to public non-federal agencies.

In summary, CIPSEA may best be utilized when a federal agency needs a rapid and widespread response to a call-for-data. However, the implementation of the protection that CIPSEA mandates is neither fast nor inexpensive. Thus, an agency would already need to have the systems and policies in place well before collecting CIPSEA-protected data. CIPSEA is not a clear win or may not even be appropriate for EWN needs.

\section{Freedom of Information Act as a data sharing mechanism}

FOIA is a mechanism for release of Federal government information to the public at large. Only public agencies are impacted by FOIA. It terms of applicability to data sharing issues within the EWN, any public/government agency that has data sharing arrangements with energy or water stakeholders will likely need some mechanism in place to protect the shared data from FOIA release. 


\section{Federal Information Security Management Act (FISMA) of 2002}

This act (1.4) was enacted as part of Title III of E-Government Act of 2002, which was established to address the "potential security threats to information and information systems in Federal agencies." FISMA requires all Federal agencies to implement security protocols/practices, for the "information and information systems that support the operations and assets of the agency, including those managed by other agencies and contractors." FISMA will be instrumental in ensuring that federal data providers have protocols in place for internal data protection. How FISMA can foster collaboration among collaborators is unclear. FISMA legislation in brief includes the following guidelines for implementations:

- Establish a comprehensive security framework to support Federal information systems.

- Effective management of security of information in Federal agencies.

- Protect Federal information systems by developing and maintaining security controls.

- Devise a system to improve the Federal information securities programs monitoring.

- Protect the critical information and infrastructures by acknowledging the use of commercial security implementations.

- Understand the need to make personalized hardware and software implementations for information security.

\section{Lessons from Other Industries}

Other industrial sectors and agencies have faced similar challenges to proprietary data sharing. In exploring the approaches used in these different industries, some common elements emerge pertaining to identification and authentication, access control techniques, encryption and data generalization/summarization. In evaluating the lessons learned from other industries (both in the private and public sector), we focused on two major components:

1. Policy issues

2. System architecture solutions

Details of each assessment follow below. The key findings of lessons learned from other domains are: Intelligence Community

- Pedigree / provenance of data

- Stakeholder consensus of standards and methodology from the beginning

US Census Bureau

- Summarization and Generalization

Department of Energy (DOE)

- Flexible infrastructure

- Beneficial to all stakeholders

Securities and Exchange Commission (SEC)

- Secure network protocols

- Data confidentiality between public/private/government entities

Food and Drug Administration

- Formalization of Data Standards,

- Confidentiality 


\section{Intelligence Community}

Policy Lesson Learned

The Intelligence Community (IC) policies on securing data are highly prescribed and very restrictive. For National Security Information (NSI) every document and paragraph has detailed classification markers that indicate what access level is required for each piece of information, which organizations can have the document, who can authorize release of the document, and how long the restrictions are in effect. These controls are mandated by federal laws, plus each organization in the IC has their own specific regulations that dictate what controls apply to what information (inter-agency regulations and controls often do not map to each other well and can even be contradictory).

Though the security mechanisms around NSI are explicit, sharing mechanisms are not. The IC has been under scrutiny for the last several years because of failures that have been attributed to lack of sharing. Organizational changes are attempting to address this, but it is unclear if that approach is effective. To date, no official law or executive order has mandated information sharing in a way that could be enforced or measured. National level efforts to address sharing issues typically look like the National Intelligence Reform Bill (media highlights in GCN 2004). A chain of blame is put in place, but the tools to implement change (which would necessarily involve security tradeoffs) are not.

The lesson for EWN is to be sure that both sharing and security policies are in place. Security is easier to quantify, enforce, and measure than sharing, so it often is the only part of the picture that is prescribed.

\section{System Architecture Lesson Learned}

Many efforts are in place in the Department of Defense (DoD) to create system architectures to facilitate data sharing. Directive 8320.2 (DTIC 2004) is one example of a Directive that "describes" such a system. This one is more specific than some in that it actually refers to specific types of system architectures and implementation technologies that could be used. Some just say "build a federated enterprise system". The issue is that so many groups/agencies are building the systems that it isn't clear that a single one or two will emerge as the ones that are actually used. The reasons for these problems are:

1. Budgetary

2. Turf-oriented

3. Incompatibility between existing legacy systems

4. Conflicting needs and even laws across the entire community

5. Building a true multi-level and multi-lateral system without air gaps is difficult and the security of such systems cannot be guaranteed, even theoretically.

The lesson for EWN is to create a well-planned right from the start. Ideally any EWN-related data infrastructure will take into account stakeholders needs, available technology, and experience. Getting the policy part right first is imperative. Data and models may not just fix your policy problems, it will expose them. 


\section{U.S. Census Bureau}

\section{Policy (and technical mechanisms) Lesson Learned}

The US Census Bureau performs a number of surveys on the nation's populous, most notably the enumeration of the country in the decadal survey. Due to the inherent privacy and security concerns in the data they collect, and the fact that trust in the Census Bureau is imperative to their functioning, the Census employ a number of privacy and security measures for their different products. What follows are the pertinent methods used by the Census Bureau:

Spatial Generalizing. The Census Bureau distribute data from the short form at different hierarchical level, the smallest being the Census Block, which can contain up to several hundred people, depending on land use. At each level (Block, Block Group, Tract, Zip Code, etc...) the data is generalized and the totals or averages for the contents of each unit are reported.

Anonymization. When examining microdata, or sample data from the "long form", the personal information is re-assigned to a random, yet unique identifier, so that the ability to reconnoiter the surveys' true identity is not evident. However robust or well intentioned, there are a number of methods that can be used, mostly through using commercial products, to re-identify the true respondents. What the Census Bureau's use of Anonymization indicates is that there is a balance between openness and security, and that in the "information age" in which we live, understanding that that balance is constantly being tested.

\section{Department of Energy (DOE)}

Computer/Network intrusion \& incident data within DOE

DOE sites, sponsoring agencies and organizations (DOE-HQ for example), law enforcement (police, FBI, counterintelligence personnel), utilities, and power companies are all key stakeholders when it comes to network intrusions and computer security incidents. Security incident sharing, i.e. reporting, is mandated by DOE Notice 205.4.

Within this community there are several convoluted relationships when it comes to sharing intrusion and incident data, a few of which are described below.

The operational and analytical elements within DOE identified the key lessons they have learned to facilitate security-conscious sharing as:

1) The data holder and other key stakeholders must be involved from the beginning i.e. grassroots as opposed to top-down policies.

2) The "system" - from both a policy and computing tools perspective - must be flexible enough and sensitive enough to live by the data holders rules.

3) The community of sharing is more likely to be effective is everyone feels they can personally benefit from data sharing..

4) Even though incident reporting is required per the DOE Notice, the degree to which that sharing happens in a way that is efficient, and useful to incident responders and analysts, is still highly dependent on the personal trust between the DOE sites and the incident response coordinators (in this case the Computer Incident Advisory Capability or CIAC). 


\section{Policy Lessons Learned}

In the DOE intrusion domain many key stakeholders have standing agreements in place that dictate the details of security and sharing. Thus, prior authorization is not required and the system can work faster. Sometimes specific analysis cases of intrusions and data necessary to perform this function are agreed to on case-by-case basis. Some agreements are very formal and include details of data backups, system accreditation, extra security controls, etc.

In the DOE incident domain, incident reporting is required per DOE Notice 205.4. However, by examining the details of Computer Incident Advisory Capability (CIAC) webpage (CIAC, 2007) that describes reporting procedures, one can see that what "reporting" entails can be interpreted in many ways, and the level of detail of the data that is shared is very much up to the sites. Note that CIAC offers computer tools and forms to encourage the sites to be forthcoming with details and encourages sharing.

The incident response community (international, not just DOE) has established an exemplary model when it comes to data sharing and security. The Forum of Incident ReSponse Teams (FIRST.org) is a community of organization representatives that perform computer incident response. FIRST policies, primarily in the form of MOAs, prescribe how data will be shared, used, and disseminated.

\section{System Architecture Example}

CIAC, housed at LLNL, acts as the incident response and analysis for DOE. This involves acquiring and analyzing data from most DOE sites, to which they do not have direct access. PNNL owns the network sensors distributed around the DOE complex. CIAC pulls the data from PNNL. All the data is raw and unsanitized. CIAC's system architecture is designed specifically to protect that data to the degree required. They have specially configured firewalls, special data and facility access controls and need-to-know groups, and custom and semi-custom enterprise software with custom security features. When sharing is agreed to (with the FBI for example), they generally sanitize and/or anonymize the data prior to dissemination, and push the data out to others. For their data, people's names, identification of specific DOE sites, IP addresses, are the data entities that are removed before dissemination generally.

\section{U.S. Securities and Exchange Commission (SEC)}

The SEC's mission is to "protect investors, maintain fair, orderly, and efficient markets, and facilitate capital formation." (SEC 2007). The area of study that interests the EWN data and information security needs is how SEC handles the sensitive data between public and private companies and works toward facilitating its mission and achieves a comprehensive security infrastructure. The SEC data relating to investors, companies, markets, finance, and other areas have implications on economy, financial market regulation, and country's security similar to protecting water and energy related data goals of EWN. For example, information security considerations and data protection of a shared data for a public-traded company will fairly assess its market capitalization by eliminating speculation and avoid unfair competitive advantage to shareholders and similar companies. Protection of water and energy data available from power plants may be a similar instance for EWN.

A recent study on the SEC's information security by the Government Accountability Office (GAO) has revealed the need for the SEC to address issues relating to the sensitive data and data security (GAO 2005). These recommendations address SEC's security shortcomings and are useful for EWN in 
assessing the data security needs, establish comprehensive security guidelines, assess risks, and provide best practices for data and application security. Additionally, periodic audits of the security system would aid in strengthening and ensuring the SEC's integrity of information security.

\section{Food and Drug Administration (FDA)}

The FDA's responsibility is to protect "the public health by assuring the safety, efficacy, and security of human and veterinary drugs, biological products, medical devices, our nation's food supply, cosmetics, and products that emit radiation." With these, FDA also has responsibilities for "advancing the public health by helping to speed innovations that make medicines and foods more effective, safer, and more affordable; and helping the public get the accurate, science-based information they need to use medicines and foods to improve their health" (Wilson 2000).

Since most of these responsibilities rely heavily on quality and sensitive personal and medical data, FDA has in place protocols for information security. According to their internal document, "Guidance for Industry: Computerized Systems Used in Clinical Trials (FDA 1999), data should be: (ALCOA)

- Attributable

- Legible

- Contemporaneous

- Original

- Accurate

In addition, all test subjects are able to access their own data, the FDA is allowed to investigate all records, according to laws, such as FDA 21 CFR 11 (FDA 1997) and Section 505(k)(2) of Food, Drug, and Cosmetic Act (FDA 1973).

From the medical trials domain, a strong analog to the EWN exists in the form of the Clinical Data Interchange Standards Consortium (CDISC). The CDISC is an organization whose goals are to make accessible the data and metadata of medical and biopharmaceutical product development (CDISC 2007).Open data exchange is indented to occur as freely as possible, overcoming the computation challenges inherent in the multifaceted nature of medical research. The details of the CDISC's data security protocols are not of import; rather their success can be used as an example of an international, multi-organization consortium overcoming logistical, governmental, and privacy concerns for a single goal.

\section{Examples of Complex Relationships between Energy and Water Entities}

To illustrate the different kinds of relationships that exist between Energy and Water entities, some examples are presented below. These are meant to demonstrate the diverse suite of issues that permeate through the Energy-Water Nexus, reaching far beyond data sharing. We found four classes of relationships that exist within the EWN:

1) Large-Scale Government Examples

2) Grass-roots relationships

3) Third-Party / Consultant Interactions

4) Native American Tribal Cases

Each can be viewed as an "endmember" along a continuum of partnerships within the EWN. Each deals with their own set of legal, financial, resource, and cultural constraints. We examined case 
studies of each class, presenting potential solutions to facilitate data sharing, identifying the key Information Security issues present in each situation and proposing potential solutions. In proposing potential solutions, however, we found solutions do not all reside in "Information Security" solution space; some are more cultural in nature.

\section{Large-Scale Government Examples}

There are three significant large-scale government-controlled Energy/Water examples in the country, each of which provides water and power to millions across many states. These are the Bonneville Lock and Dam on the Columbia River between Oregon and Washington State, The Hoover Dam on the Colorado River bordering Arizona and Nevada, and the Tennessee Valley Authority in the Tennessee Valley. Here we focus on the Tennessee Valley Authority (TVA). While its government control might suggest the potential for simple relationships between the energy and water interests, it is a complex situation, in which energy and water issues are worked based on interpersonal relationships at the individual level as much as large-scale institutional agreements.

\section{Case Study: The Tennessee Valley Authority}

The TVA was formed in 1933 as a Federally-owned corporation to provide solutions to a multitude of problems in the Tennessee Valley region, specifically power production, navigation, flood control, malaria prevention, reforestation, and erosion control (TVA, 2007). As the United States' largest public power company, it provided more than 170 billion kilowatt-hours of electricity in 2005, through hydroelectric generation (10\%), fossil-based generation (62\%), and three nuclear plants $(28 \%)$. The TVA sells power to 158 local distributors, serving 8.6 million people and 650,000 businesses in seven states; Tennessee, Alabama, Georgia, Kentucky, Mississippi, North Carolina, and Virginia. The TVA also operates 49 dams and reservoirs on the tributaries of the Tennessee River, which also functions as a waterway for barges and recreational use. The TVA also manages 293,000 acres of land and performs flood control duties for that land.

A number of "big players" have responsibilities in the region and the issues that follow. These include the TVA itself, as a "regional development agency" (TVA, 2007) that provides electricity and manages water quality and transportation ability, the US Bureau of Reclamation and the Army Corps of Engineers who built and manage the dams and locks, as well as the Southeastern Power Administration (SEPA), whose aim is to market and deliver the cheapest power to people of the Southeast. Additional stakeholders that relate tot eh TVA include the seven states, and the many municipalities that lie within its boundaries.

Creating a locus for integrated planning of water and Energy within the TVA is no small task. The stakeholders have been known to "play their cards close to their chest" and keep data and models as internal products, reluctantly releasing data to other agencies. Advances in data sharing are a function of the strength of one-on-one personal relationships of managers in different stakeholder groups. Additionally, data are in different formats with unique schema (Brennan Smith, ORNL, 2007, Personal Communication). 


\section{Potential solutions}

Focus on: integrity, authenticity, utility

- Open, top-down data administration

Large-scale government and corporate stakeholders need a system that stresses coordinated openness of standards-based data sharing, currently in place by Federal E-government initiatives.

- Leverage current infrastructure

The efforts already in place by organizations like the USGS and the EPA could be leveraged and added to reduce duplication of work. Leadership by EIA would be most appropriate since the Agency already collects and distributes energy and water data. This would expand the leadership and coordination role that the EIA currently plays.

A clear first step is to leverage current in-place government-sponsored data sharing resources, such as the National Information Exchange Model (NIEM.gov). NIEM is a multi-level government initiative (including Tribal Nations) to provide a foundation for sharing data for public safety, justice, emergency and disaster management, intelligence, and homeland security. NIEM was founded in 2005 by the Departments of Justice and Homeland Security and currently has in-place tools for working with the data sharing protocols. NIEM uses standards-based data sharing methodologies, to leverage current data resources.

\section{Grass-roots relationships}

In the US, many power companies and water entities forge their own relationship on an as-needed or ad-hoc basis, either by plan or necessity, such as drought or increased demand. It is challenging to make generalizations about these grass-roots relationships due to their unique and potentially ephemeral nature. Some grass-roots relationships are formed for a few years, or just a few months, to help a power company "get by" in stressed times. These grass-roots relationships can be made between types of players of all sizes, be they federal, state, co-ops, private or regional.

The unique nature of grass-roots relationships creates unique data-sharing challenges. When a relationship or problem is stated or proposed, there is no search for appropriate data and model results; rather the power companies look for available water that is close and cheap, be it from an agricultural source, river source, or waste municipal source. This search could be more efficient if there was a consistent place to search for data and models describing water availability, but this is not the method of operations to date. What follows are two examples from the Western US - one from Wyoming, one from California, the first formed by short-term need, the second by regulatory necessity.

\section{Case Study: The Laramie River Station}

In the dry plains of Eastern Wyoming, the Laramie River Station provides energy to customers in Colorado, Nebraska and Wyoming by burning coal. The plant is owned by the Missouri Basin Power Project (MBPP), a consortium of six electric utilities, and operated by Basin Electric Power Cooperative (BEPC) (also a 42.27 percent owner). Each of the six co-owners is a "Co-op" utility, and their headquarters are located in Nebraska, Colorado, and Wyoming, as well as South Dakota (BEPC, 2007).

The Laramie River Station is novel because it provides electricity to both the Eastern and Western Interconnect. The water used to cool the Laramie River Station comes from the nearby Grayrocks Dam 
and Reservoir, also operated by the MBPP. Due to a long drought in the area, there was an unsustainable amount of water in the Grayrocks Reservoir to supply the Laramie River Station, and in 2004 the MBPP began purchasing water from local irrigators for supplemental water. Currently water comes from both the dam and 35 local wells (Hill, 2005). It should be noted that the Grayrocks Reservoir is also administered by the Bureau of Land Management (BLM) for recreation and fishing uses. There are also a number of sensitive species in the region as well.

This example illustrates how a co-op draws its "own" water; water it manages in addition to water from individual privately owned irrigator's wells. The arrangement between Basin Electric and the local irrigators was an ad-hoc necessity, based on emerging needs. The future of the MBPP-local irrigator relationship is uncertain, but highly dependent on the amount of rainfall available to fill up Grayrocks Reservoir. However, we conjecture that since the foundation has been laid, MBPP may draw on local water as a reserve when water, or the ability to use water, is scarce. While this example illustrates how the ability to anticipate the long- and short-term consequences of a drought can lead to the creation of an ad-hoc relationship, the presence (or absence) and available data (and models) can help mitigate and facilitate the creation of such relationships.

\section{Case Study: California, Power Plants, and Water}

In recent years California has felt pressure for increased capacity of electricity at one end, and water scarcity on the other. Facing pressure from these domains, the California Energy Commission (CEC) has made proactive policy to address the Energy-Water conflict. In 2003, the CEC made a policy so that no new power plants drawing fresh water would be approved, unless no "environmentally desirable" alternatives exist (CEC, 2003). In 2005, the CEC had strong (but not as strong) policy adopted towards once-though cooling as applied to Ocean Water (CEC, 2005). These policies led to two steps in the power plant approval process:

1) Addressing that water for cooling is an important component of power plant planning

2) Conversing with the CEC about water needs can help facilitate power plant approval.

As an example of amended power plant cooling plans occurred is the Tesla Power Project in Alameda County. In 2001, Midway Power, LLC proposed to construct a 1,120 MW natural gas-fired power plant in rural Alameda county. Originally the project was to draw water from the nearby California Aqueduct, yet after discussion with the CEC, the project is now slated to draw reclaimed water derived from wastewater from the nearby city of Tracy. The project, though originally approved, is currently "On Hold" due to California's restructuring of their electricity infrastructure (CEC, 2004). While data access and sharing at the Tesla plant was not a component of the CEC's decision making process, we posit that a transparent system where data can be accessed and shared would aid in the process of choosing water (conventional and alternative) for proposed energy projects.

\section{Potential Solutions}

Focus on: confidentiality, possession / access control

- Peer-to-peer networks

The use of open-source peer-to-peer networks can enable expedient data transfer without large-scale data infrastructures. Collaborative protocols aid in stakeholder buy-in and can facilitate data sharing.

- Guidelines and standards-based methodologies for data generalization

Getting data into the correct format, based on any standard, could be an issue. Especially of concern is making sure data can be cross-walked, once made available for sharing. Generalizing data to protect 
proprietary interest may be a valuable technique. Consistent generalizing with respect to space and/or temporal resolution needs to be put in place.

- Protection of proprietary nature of data

Tracking of data delivery, ownership and utility will be of high importance. Protections similar to that of the Recording Industry Association of America's (RIAA), especially pertaining to the distribution of digital music, may be a good model to follow.

\section{Third-Party / Consultant Interactions}

Due to the administrative challenges of providing Energy and Water services to the public, it is not surprising for cities and municipalities to out-source the management of to outside consultants. Consulting companies can provide detailed analysis and modeling tools for planning and strategizing, and can used at a savings relative to doing the work in-house. The use of consulting companies is not the most common of relationship; rather it presents a different set of challenges to data sharing from the previous two categories. New York City will be used to illustrate how third-party interactions can unfold.

\section{Case Study: New York City's Challenges}

As the economic capital of the US for over 150 years, New York City has depended on plentiful water and energy for its industry, commerce and citizens. The infrastructure that supports NYC is aging and the available power supply is falling short of future demand estimates. A 2004 study concluded that New York City will need an additional 2600MW by 2010 (NYC Energy Policy Task Force, 2004). To date, the City Energy and Water planning has assumed that there would be enough water to supply that power, and along parallel lines, assumed that there would be enough power to support the deliver of water to its citizens (BNL, 2004). Additionally, the deregulation of the power industry in the state has led to challenges in integrative planning. Most power plants for the city lie on or near the City's waterfronts, due to water and access to shipping routes. The New York State Department of Environmental Conservation will no longer allow for the use of river water for cooling of power plants.

The major players in NYC's are the New York State Energy Research and Development Authority (NYSERDA), the New York Power Authority, Con Edison, and the City itself. Within the city, numerous agencies administer over and write policy on water and energy. Many of these city agencies use independent consulting companies for data collection and analysis. This has led to the situation where data is housed at these consulting companies, not at the city, and when outside entitles (or other consulting companies) want access to these data, they are put in the position of either being denied access to it due to the proprietary nature of the data (which is technically owned by the City). The collaborative nature of energy water integrated planning is not easily facilitated under such conditions (Kenya Crosser, BNL, 2007, Personal Communication).

\section{Potential Solutions}

Focus on: possession / access control, utility

- City takes ownership

Since the data is at the center of the conflict, the city must take control of the issues, centering on the data which they rightfully own. Once all data is collected, it can be formulated in a consistent manner, according to standards from a consensus of consulting companies.

- Partner with State and consulting companies 
By collaborating on planning with the State as well as consulting companies, clear goals can be set and individual tasks can be managed, to maximize appropriate data usage.

- Centralized control

The city centralizes control of data through licensing it tp consulting companies, in order to track and manage data usage.

\section{Native American Tribal Cases}

Native American Tribes form autonomous governments within the U.S. Most Indian Reservations are located in the western us and have scant natural resources, including water. The Reservations can be quite large, however; in Arizona, the Native American lands comprise approximately a third of the state. Some Reservations sit on valuable aquifers and coal reserves, making them significant participants in the EWN. A group of federally recognized Native American Tribes formed the Council of Energy Resources Tribes (CERT); its goal is to "support member Tribes as they develop their management capabilities and use their energy resources as the foundation for building stable, diversified self-governing economies" (CERT, 2007). CERT provides a number of important stewardship activities for the tribes, as individually and collectively, including Strategic Planning, Policy Advocacy, Technical Assistance, Education, Energy Capacity Building, and fostering partnerships. The last of these refer to both partnerships between tribes, between corporate partners, and different sectors of the Federal government. However well intentioned CERT is, a 2003 LLNL report examining technical water issues of California Tribal Nations highlighted a number of constraints on information sharing with respect to the Tribes (Ben and Coty, 2003).

These obstacles pertain to water specifically; if water and energy are to be considered together, then the compounded challenges may be multitudinous. The general categories of these information-based challenges as pertaining to water are:

1) Water information currently sensitive due to litigation

2) No key water contacts in the many Indian Federal agencies.

3) Lack of clear jurisdictional boundaries of Indian Federal Agencies and protocols of confidentiality. The myriad of Federal agencies a single tribe an interact with include:

a. Bureau of Indian Affairs (BIA)

b. Environmental Protection Agency (EPA)

c. Indian Health Services (IHS)

d. U.S. Department of Agriculture (USDA)

e. Bureau of Reclamation (BOR)

4) Unique government structure and disclosure policies in tribes can make information gathering difficult.

5) Lack of trust between Federal and Tribal governments

6) Lack of water or environmental staff in Tribal governments

Ben and Coty 2003

\section{Case Study: Coal and Water in the Four Corners}

Citing water supply issues, the Hopi and Navaho Nations, the tribes that own the most land in the Four Corners region of the Southwest (where Arizona, Colorado, Utah, and New Mexico meet) have acted to stop the use of a coal slurry system (Steve Grey, personal communication, 2006). Tribes have also cited inequity of Energy distribution as an obstacle to Electricity development. Specifically frustrating 
the tribes are realized scenarios where power lines cross Tribal lands while many members of the reservation have no connection to the grid themselves (SEC, 2007).

The challenges facing Tribal governments with respect to water alone illustrate that technological solutions alone will not smooth a path of information sharing. There are real cultural and logistical issues surrounding water and energy issues.

\section{Potential Solutions}

Focus on: possession / access control, utility

- Acknowledge cultural differences

Addressing the sensitivity of the Tribal Nations perspective may help buy-in. Additionally, the value patience and understanding cannot be overlooked.

- Clarity about ownership of resources

It must be explicit that the Tribes own their data and any planning activity using those data is akin to similar ownership.

- Shared control between tribes

While each Tribe is unique with unique energy and water issues, collectively they may be able to share control of their data, to reduce overhead and leverage previous data organization infrastructure.

- Data transfer as currency

By viewing data as currency, the value of data rises. The creation of a market, with protections and protocols analogous to financial markets will markets will give the impression, legitimately, that data will be protected at the utmost expense.

- Data Library (check in- check out)

Data will be protected and use will be monitored and recorded.

- Secured network with distributed and documented control

A sensitive g environment would greatly benefit from a data sharing system that can be secure to stakeholders, yet secure to inappropriate use or distribution.

\section{Hybrid relationships}

\section{Case Study: Agriculture - Hydropower electricity integration in the Pacific Northwest: a work in progress}

Pacific Northwest National Laboratory (PNNL) is working with the Bonneville Power Administration (BPA) to explore using smart metering of agricultural pumping as a conservation method to current hydropower generation demand. The goal of this project is to create an optimized system where the supply for electricity demand for electricity for pumping would be directly integrated with the power would be generated according to water-pumping demand, from the cheapest and most readily available source, as well as pumping being delayed until prices (and electricity availability) subside. The future of the region faces increased overall electricity demand in the region, coupled with the uncertainty of water availability (for hydro power); producing excess power through hydro when not ultimately necessary is sub-optimal (Lance Vail, PNNL, 2007 Personal Communication).

This example illustrates components of both the "Large-scale Government" and "Grass-roots" relationships, where a single government entity (BPA) will interact with a multitude of independent 
and regional participants (the farmers). Data sharing is critical in this example and will heavily rely on open data transfers, mostly from the "smart meters" of the farmers' water pumps delivered to the BPA. The BPA is very enthusiastic about this project, while the farmers (clearly not a unified force) range from being apathetic to being marginally interested. Clearly, the benefits for such a "smart metering" system are clearly more visible to the BPA, who benefit from collective small actions. If the BPA construct a system that makes it beneficial for the farmers, with low capital and annual costs, the farmers may become more enthusiastic. There is currently no plan in this project to address the various attitudes and perspectives of the farmers.

\section{Decision Tools for Energy-Water Management}

Sandia National Laboratory (SNL) is currently developing tools for State-level decision-making for integrated energy-water management. According to Vince Tidwell (Personal Communication, 2007), the goal of the tool is to evaluate trade-offs of the range of portfolio options over time, specifically those related to electricity generation, cost, water use, emissions and pollution. SNL aims to create a tool for analysis at a variety of scales, from regional to national and incorporate power and population projections.

A challenge for the SNL work is the nature of data - energy data is available from national sources (like EIA) at the utility level, while water data is available at the watershed level, when available. The nature of the aggregation and scales of the data will make for a challenge in understanding the flows and transportation of water and energy challenge, let alone the future forecasted amount of energy and water.

\section{Choosing Appropriate Security for Data Sharing Activities}

When determining the appropriate security and format for optimal data sharing activities within the EWN, one should determine whether a single methodology would work for all possible permutations or if each class of relationship necessitates it own data sharing formulation. The advantages of a single broad-based infrastructure are numerous. Data formats would be standardized, security could be universally maintained, and data ownership and utility could be carefully observed. However, the case studies presented in this work suggest that data security is not the limiting factor in data sharing. Primarily, the single most prevalent obstacle in data sharing is human nature. People, particularly corporations, and government agencies to a lesser degree, are weary of loosing control of their data, and of the potential consequences of that loss. Some of these fears are legitimate, as in corporate secretes becoming public, while others are more suspect, like federal data stewards not releasing data to those they don't know, trust, or like. This reduces the significance and impact of the social dynamics of data sharing. Rather, it emphasizes that the framework of data sharing within the EWN must address the human factor in the equation.

Ideally any data system (with appropriate security constraints) would be a synergistic, time saving operation, helping stakeholders streamline and standardize data, shore up their own system security, and directly address the goals of the integrated modeling. Rethinking data format, security and distribution, could aid both the energy and water industries internally, much as computer equipment and computer code were replaced and upgraded of in preparation of the $\mathrm{Y} 2 \mathrm{~K}$ bug. 
The main dichotomy in the types of relationships that need different kinds of data sharing mechanisms is between "Large Infrastructure" and "Grass-roots infrastructure". One can assume that the large scale Governmental projects and organizations can rely on the power of Federal protection, as well as collaborative help from Federal agencies. On the local scale, smaller projects will have to create their own links and data sharing mechanisms, unless through collaborative demonstration projects, suggestions and tools can be created to facilitate the free and open exchange of data to relevant parties, with appropriate protection and safeguards.

The multifaceted role of consulting companies in the EWN is an interesting revelation. On one hand, consulting companies collect data and provide simple analysis for decision makers for corporate interests. With the Tribal Nations, on the other hand, consulting companies provide richer analysis and policy suggestions for their stakeholders. The role of these third parties and their claims of ownership and proprietary information over explicitly public data warrant additional investigation.

\section{Conclusions}

The key to integrated planning in the Energy-Water Nexus is open collaboration between stakeholders. Yet before collaboration begins, stakeholders have to commit to working together, at least to achieve their individual goals. Before the discussion of data and models begins, stakeholders need to address their personal and organizational concerns, as successful relationships between stakeholders are imperative in this process. Participants in integrated EW planning seeking consensus at this stage might benefit by following the "Operating Principles for Data Access Regimes" suggested by Arzberger et al (2004), which include

1) Openness Transparency and active data dissemination

2) Assignment and assumption of formal responsibilities

3) Technical and semantic interoperability of databases

4) Quality control, data validation, authentication, and authorization

5) Operational efficiency and flexibility

6) Respect for intellectual property and other ethical and legal requirements

7) Management accountability, including funding approaches

Once stakeholders can identify common goals and data needs, the nature of the relationship and type of entity involved will determine the appropriate security and data sharing mechanism. This can be greatly aided by tools such as:

1) Published data and security standards.

2) Readily available case studies of success stories.

3) People who can facilitate the data sharing.

4) Available technological infrastructure to take advantage of the best and newest computer network tools.

As evidenced in the case studies, there is no cookie-cutter recipe for secure data sharing. Information security within the EWN necessitates understanding of the relationships, data needs and cultural context of the stakeholders involved. However, through mutually agreed upon and consistent data sharing, modeling, and, in turn, integrated planning, energy and water needs can be met at the local, regional and national level. 


\section{Acknowledgements}

The authors would like to thank a number of in-house and external collaborators on this project. At LLNL we would like to thank Bill Bourcier, Zafer Demir, Jesse Coty and Steve Grey; and Larry Dale from LBNL. We would also like to the thank the following people who contributed tot his work through conversations or emails: Robert Goldstein at EPRI, Craig Eaker from SoCal Edison, Joe Henri, Gary Freeman, and Randy Livingston from PG\&E, Ted Howard at the CPUC, Shahid Chaudhry, Bob Wilkinson, Martha Brook, Joe O’Hagan from the CEC, Art Diem at the EPA, Jay Casselberry, at EIA,

This work was performed under the auspices of the U.S. Department of Energy by University of California, Lawrence Livermore National Laboratory under Contract W-7405-Eng-48, and Lawrence Berkeley National Laboratory under Contract DC-AC02-05CH11231. 


\section{References}

Arizona Department of Water Resources (2007) “Arizona Drought Program Community Water System Information" www.azwater.gov/dwr/drought

Arzberger,P., Schroeder,P, Beaulieu,A., Bowker, G. Casey,K. Laaksonen, L., Moorman,D., Uhlir, P, and Wouters, P. (2004) "An International Framework to Promote Access to Data" Science, 19 March 2004: Vol. 303, No. 5665, pp. 1777 - 1778.

Basin Electric Power Cooperative (2007) Laramie River Station www.basinelectric.com/EnergyResources/Electricity/BaseLoad/LRS.html

Ben, C and Coty J. (2003) California Tribal Nations Technical Water Research Technical Report, UCRL-TR-21473 Lawrence Livermore National Laboratory, Livermore, California.

Brookhaven National Laboratory (BNL) (2004) New York Regional Energy-Water Workshop Summary www.bnl.gov/est/workshop/WorkshopSummary/Workshop_Report_TrendsIssues.pdf

Brown, T.C. (2000) "Projecting U.S. freshwater withdrawals" Water Resources Research, Vol. 36, No. 3, pp. 769-780.

California Public Utilities Commission (2005) Water Action Plan, www.cpuc.ca.gov/Static/hottopics/3water/water_action_plan_final_12_27_05.pdf

California Energy Commission (CEC) (2003) Integrated Energy Policy Report, Docket \#02-IEP-01, www.energy.ca.gov/2003_energypolicy/index.html

CDISC (2007). Clinical Data Interchange Standards Consortium, "Mission and Strategy" http://www.cdisc.org/about/index.html

CEC (2005) 2005 Integrated Energy Policy Report: Commission Final Report, Publication \# CEC100-2005-007-CMF, www.energy.ca.gov/2005_energypolicy/index.html

CEC (2004) Revised Presiding Member's Proposed Decision, www.energy.ca.gov/sitingcases/tesla/documents/2004-05-13_REVISED_PMPD.PDF

Computer Incident Advisory Capability (CIAC) (2007), http://www.ciac.org/ciac/incidentreporting.html accessed March 2007.

Congressional Budget Office (2002) "Drinking Water and Wastewater Infrastructure", Future Investment in Drinking Water and Wastewater Infrastructure, www.cbo.gov/showdoc.cfm?index $=3983 \&$ sequence $=2$

Council of Energy Resources Tribes (2007), “About CERT”, www.certredearth.com/about.php, accessed September 2007. 
DTIC (2004), Directive 8320.2 "Data Sharing in a Net-Centric Department of Defense" December 2, 2004, http://www.dtic.mil/whs/directives/corres/pdf/832002 120204/832002p.pdf accessed March 2007.

Energy Information Administration (1999) "Chapter 5" Electric Power Annual 1998, Volume II, DOE/EIA-0348(98)/2, Washington, DC, www.eia.doe.gov/cneaf/electricity/page/prim2/chapter5.html

Energy Information Administration (2004), "Electricity Market Module of the National Energy Modeling System, Model Documentation Report 2004”, DOE/EIA-M068(2004), tonto.eia.doe.gov/FTPROOT/modeldoc/m068(2004).pdf

Energy Information Administration (2007) "About Us", EIA Website, www.eia.doe.gov/neic/aboutEIA/aboutus.html

EPRI (2002) Water and Sustainability (Volume 3): U.S. Water Consumption for Power ProductionThe Next Half Century, EPRI, Palo Alto, CA

EPRI (2003) A Survey of Water Use and Sustainability in the United States With a Focus on Water Use in Power Generation, EPRI, Palo Alto, CA.

FDA (1999) “Guidance for Industry: Computerized Systems Used in Clinical Trials” http://www.fda.gov/ora/compliance_ref/bimo/ffinalcct.htm

FDA (1997) "FDA 21 Code of Federal Regulations Part 11; Electronic Records; Electronic Signatures of 1997”, http://www.fda.gov/ora/compliance_ref/part11/

FDA (1973) "The U.S. Food and Drug Administration, Federal Food, Drug, and Cosmetic Act; Chapter V, Drug and Devices, Section 505(k)(2)", http://www.fda.gov/opacom/laws/fdcact/fdcact5a.htm

GAO (2005), "INFORMATION SECURITY: Securities and Exchange Commission Needs to Address Weak Controls over Financial and Sensitive Data"; Report to the Chairman, SEC; United States Government Accountability Office; http:/www.gao.gov/new.items/d05262.pdf

Government Computer News (GCN) (2004), "Final intelligence reform bill stresses data sharing" http://www.gcn.com/print/23_34/28097-1.html December 13, 2004.

Getis, A. (1999) "Some thoughts on the impact of large data sets on regional science", Annals of Regional Science, Vol 33, pp. 1245-150

Gleick, P. H. (1998) "Water in crisis: paths to sustainable water Use”, Ecological Applications Vol. 8, pp. 571-579.

Hill, D. (2005) “Water Woes Worrisome”, Basin Today. July/August 2005

Hutson, S. (2005) Estimated Use of Water in the United States in 2000 USGS Circular 1268. revised February 2005, United States Geological Survey, Washington DC. 
Mann, P.C. (1993) Water-Utility Regulation: Rates and Cost Recovery, pp: 6-8, www.reason.org/ps155.html

NYC Energy Policy Task Force (2004) New York City Energy Policy: An Electricity Resource Roadmap. www.nyc.gov/html/om/pdf/energy_task_force.pdf

Neal, K. (1996) Restructuring America's Water Industry: Comparing Investor-Owned and Government Water Systems, www.reason.org/ps200.html

Nedovic-Budic Z. and Kim, J.T. (1999) "Introduction to the Special Issue on Geospatial Data Sharing and Standardization”, Special Issue of the Annals of Regional Science, Vol. 33-2, pp. 141-144, Springer-Verlag, Berlin.

Parker, D.B. (1995) "Using threats to demonstrate the elements of information security", Proceeds of the European Convention on Security and Detection, p. 11 -17 Brighton, UK, 16-18 May 1995.

SEC 2007 . Securities and Exchange Commission Website ww.sec.gov/about/whatwedo.shtml

SCE (2007) Mohave Generation Station,

www.sce.com/PowerandEnvironment/PowerGeneration/MohaveGenerationStation

TVA (2007) From the New Deal to a New Century: A short history of TVA, www.tva.com/abouttva/history.htm.

U.S. Census Bureau (2005) "Table A1: Interim Projections of the Total Population for the United States and States: April 1, 2000 to July 1, 2030”, Population Division, Interim State Population Projections, 2005.

Wilson, J.P., Mitasova, H., and Wright, D.J.(2000) "Water resource applications of GIS", Journal of the Urban and Regional Information Systems Association, Vol. 12, No. 2, pp. 61-79. 